\title{
Prevalence of Contraceptive Used by Married Couples in Chattogram Hill Tracts

\author{
Zafreen $\mathrm{F}^{1}$, Rahman $\mathrm{MM}^{2}$, Razzak $\mathrm{MA}^{3}$, Rahman $\mathrm{MH}^{4}$, Wahab $\mathrm{MA}^{5}$
}

DOI: https://doi.org/10.3329/jafmc.v14i2.45889

\begin{abstract}
Introduction: Bangladesh is a densely populated country with high fertility rate. Contraception is an essential method for reducing fertility rate. Use of contraceptive depends on couples' socio-cultural, education and economic condition. Chattogram hill tract is the least economically developed area where, education and health care facilities are hard to reach.
\end{abstract}

Objectives: To find out the prevalence of contraceptive used bymarried couples of selected rural community of Khagrachari District.

Materials and Methods: This descriptive cross sectional study was conducted from January to December 2017on 300married women age ranging from 15 to 45 years reported to outpatient department of Border Guard Hospital,Guimara,Khagrachari were selectedpurposively after informed written consent.All the necessary data were collected in a pretested structured questionnaire by face to face interview.

Results: Among the 300 respondents highest $42.7 \%$ was in age group of $15-25$ years, $60 \%$ were married for more than 10 years, $38.3 \%$ were illiterate, $89.7 \%$ were housewives and $55.7 \%$ had monthly family income between five to ten thousands taka. Respondents' ethnicity was Bengali 51.7\%, Marma 18.3\%, Tripura $18.7 \%$ and Chakma 34(11.3\%). About 53\% respondents were using contraceptives among them $95.6 \%$ were using temporary methods; $60.4 \%$ oral contraceptive pill followed by injectable $15.8 \%$ and condom $9.4 \%$. Barrier to contraceptives use was fear of side effects $21.9 \%$ followed by husbands' non co-operation $24.9 \%$ and religious bar $22.7 \%$.

Conclusion: Prevalence of contraceptive use in Chattogram Hill Tract is lower than the overall rate of the country. Appropriate measure should be taken to increase the contraceptive use rate so that total fertility can be controlled.

Key-words: Contraceptive method, Married women, Chattogram hill tracts.

\section{Introduction}

Bangladesh is one of the most densely populated countries in the world with a high fertility rate ${ }^{1}$. Contraception is an essential method for reducing fertility rate ${ }^{2}$. Use of contraceptive depends on couples' socio-cultural, education and economic condition ${ }^{3}$. In Bangladesh, population planning was seen as an integral part of the total development process ${ }^{4}$. For this reason, modern contraceptive methods are easily available at all health care facilities including community clinics and family planning outreach centers, almost free of charge ${ }^{5}$. Family planning visitors routinely visit the married couples in rural communities of Bangladesh. Various types of contraceptive methods are now available in the community to fulfill the aim of family planning ${ }^{6}$. These methods can again be classified into temporary including hormonal contraceptives, condoms, IUDs and implants and permanent methods includingtubectomyfor female and vasectomy for male ${ }^{7}$.

In spite of availability of a wide range of contraceptives and mass media campaigns and information, education and communication programs, the population control remains a distant dream to achieve the target. Though birth control is the responsibility of both the partner and contraceptive methods for both men and women are available but women's contraceptive prevalence rates are higher than the men's in a developing society like Bangladesh. Reasons are related to socio-cultural status, family authority, economic freedom and education status of couple ${ }^{8}$. Contraceptive method choice is a fundamental indicator of quality of care in a family planning program ${ }^{9}$. The permanent method users are found less in number in comparison to people using temporary and long acting methods. A lack of knowledge of contraceptive methods or a source of supply and poor accessibility are the barriers that exist in developing countries ${ }^{10}$. Bangladesh has improved a lot in the field of birth control and contraceptive use but this improvement is not equal throughout the country. Chattogram hill tract is the least develop area of Bangladesh, where education rate is low and health care facilities are hard to reach. To find out the prevalence of contraceptive used by the married couple of Chattogram hill tract this study was designed.

\section{Materials and Methods}

This descriptive cross sectional study was conducted from January to December 2017 at outpatient department (OPD) of Border Guard Hospital, Guimara, Khagrachari. A total of 300 married women age ranging $15-45$ years reported to OPD were selected purposively as study subject. After assuring secrecy and not revealing individual identity informed written consent was taken before collection of data. All the necessary data were collected in a pretested structured questionnaire by face to face interview. Collected data were analyzed by SPSS for Windows 20.0 and presented as frequency and percentage.

1. Dr Farzana Zafreen, MBBS, MPH, Associate Professor \& Head, Department of Community Medicine, Medical College for Women \& Hospital (E-mail: farzana_zafreen@yahoo.com) 2. Maj Gen Md Mustafizur Rahman, MBBS, MPH, MBA, FCGP, Ex-Commandant, Armed Forces Medical College (AFMC), Dhaka 3. Brig Gen Md Abdur Razzak, MBBS, MCPS, FCPS, APLAR Clinical Fellow Rheumatology, Professor and Head, Department of Medicine, AFMC, Dhaka 4. Brig Gen Md Habibur Rahman, MBBS, FCPS, Professor, Department of Medicine, AFMC, Dhaka 5. Lt Col Md Abdul Wahab, MBBS, MD, Associate Professor of Biochemistry, AFMC, Dhaka. 


\section{Results}

Among the 300 respondents highest number $128(42.7 \%)$ was in age group of $15-25$ years andmajority $163(54.3 \%)$ were follower of Islam followed by Hinduism 64(21.3\%) and Buddhism 49(20.3\%). Respondents' ethnicity was Bengali $51.7 \%$, Marma 18.3\%, Tripura $18.7 \%$ and Chakma34(11.3\%). Majority $180(60 \%)$ respondents were married for more than 10 years and $115(38.3 \%)$ were illiterate. Majority of the respondents were housewives $269(89.7 \%)$ and $167(55.7 \%)$ had monthly family income between five to ten thousands taka (Table-I). Among the respondents $159(53 \%)$ were using various types of contraceptives in contrary $141(43 \%)$ were not using any contraceptives for various regions (Figure-1). Respondentsusingcontraceptives weretemporary methods $152(95.6 \%)$ and permanent methods only $7(4.4 \%)$. Among thecontraceptives usersoral contraceptive pill (OCP) was highest $96(60.4 \%)$ followed by injectable $25(15.8 \%)$ and condom 15(9.4\%) (Table-II). Respondents got information about contraceptives mostly from family planning workers $139(46.4 \%)$ followed by relatives 76(25.3\%) and quacks 34(11.3\%) (TableIII). Barrier to not using contraceptives was fear of side effects $31(21.9 \%)$ followed by husbands' non co-operation 35(24.9\%) and religious bar 32(22.7) (Table-IV).

Table-I: Socio-demographic characteristics of respondents $(\mathrm{n}=300)$

\begin{tabular}{|c|c|c|c|}
\hline \multicolumn{2}{|c|}{ Characteristics } & Frequency & Percentage \\
\hline \multirow{3}{*}{ Age in years } & $15-25$ & 128 & 42.7 \\
\hline & $26-35$ & 83 & 27.7 \\
\hline & $36-45$ & 89 & 29.6 \\
\hline \multirow{4}{*}{ Religion } & Islam & 163 & 54.3 \\
\hline & Hinduism & 64 & 21.3 \\
\hline & Buddhism & 49 & 20.7 \\
\hline & Christianity & 11 & 3.7 \\
\hline \multirow{4}{*}{ Ethnic group } & Bengali & 155 & 51.7 \\
\hline & Marma & 55 & 18.3 \\
\hline & Tripura & 56 & 18.7 \\
\hline & Chakma & 34 & 11.3 \\
\hline \multirow{4}{*}{ Duration of marriagein years } & $1-5$ & 53 & 17.7 \\
\hline & $6-10$ & 67 & 22.3 \\
\hline & $11-20$ & 112 & 37.3 \\
\hline & $>20$ & 68 & 22.7 \\
\hline \multirow{4}{*}{ Education status } & Illiterate & 115 & 38.3 \\
\hline & Primary & 94 & 31.3 \\
\hline & Secondary & 59 & 19.7 \\
\hline & Above secondary & 32 & 10.7 \\
\hline \multirow{2}{*}{ Occupation } & Housewife & 269 & 89.7 \\
\hline & Working & 31 & 10.3 \\
\hline \multirow{3}{*}{ Monthly family income in Taka } & $<5000$ & 91 & 30.3 \\
\hline & $5000-10000$ & 167 & 55.7 \\
\hline & $>10000$ & 42 & 14.0 \\
\hline
\end{tabular}

\section{Contraceptive status}

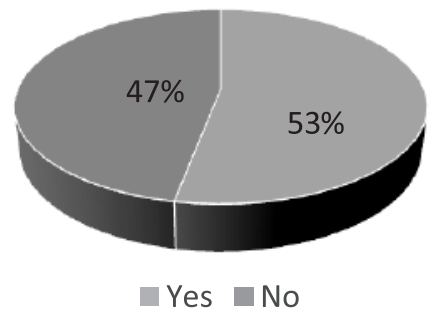

Figure-1: Contraceptive using status $(n=300)$
Table-II: Distribution of respondents by the type of contraceptive used $(n=159)$

\begin{tabular}{|l|l|r|r|}
\hline \multicolumn{2}{|c|}{ Type of contraceptives used } & Frequency & Percentage \\
\hline \multirow{4}{*}{ Temporary methods } & OCP & 96 & 60.4 \\
\cline { 2 - 4 } & Condom & 15 & 9.4 \\
\cline { 2 - 4 } & Injectable & 25 & 15.8 \\
\cline { 2 - 4 } & Implant & 7 & 4.4 \\
\cline { 2 - 4 } & IUDs & 9 & 5.6 \\
\cline { 2 - 4 } & Total & 152 & 95.6 \\
\hline \multirow{4}{*}{ Permanent methods } & Tubectomy & 5 & 3.1 \\
\cline { 2 - 4 } & Vasectomy & 2 & 1.3 \\
\cline { 2 - 4 } & Total & 7 & 4.4 \\
\hline
\end{tabular}

Table-III: Distribution of respondents by source of information about contraceptive $(n=300)$

\begin{tabular}{|l|c|c|}
\hline Source of information & Frequency & Percentage \\
\hline Family planning worker & 139 & 46.4 \\
\hline Relatives & 76 & 25.3 \\
\hline Husband & 23 & 7.7 \\
\hline Mass media & 13 & 4.3 \\
\hline Quacks & 34 & 11.3 \\
\hline Qualified doctors & 7 & 2.3 \\
\hline Others & 8 & 2.7 \\
\hline Total & 300 & 100 \\
\hline
\end{tabular}

Table-IV: Distribution of respondents by barriers to use contraceptives $(n=141)$

\begin{tabular}{|l|c|c|}
\hline Barriers to use contraceptive & Frequency & Percentage \\
\hline Fear of side effect & 31 & 21.9 \\
\hline Eager to conceive & 22 & 15.6 \\
\hline Non co-operation of husband & 35 & 24.9 \\
\hline Religious bar & 32 & 22.7 \\
\hline Ignorance about the method & 11 & 7.8 \\
\hline Others & 10 & 7.1 \\
\hline Total & 141 & 100 \\
\hline
\end{tabular}

\section{Discussion}

This descriptive cross sectional study was aimed at to find out the prevalence of contraceptive devices among 300 females in rural area of Chattogram Hill Tract of Bangladesh. In our study, about $42.7 \%$ respondents were in age group of 15-25 years which is consistent with studies done by Kamal Net $\mathrm{al}^{11}$. Ethnicity, religion and education status is consistent with the demographic data of Khagrachari district ${ }^{12}$. In the current study $60 \%$ respondents were married for more than 10 years and $89.7 \%$ were housewives,this finding differ with the suudy of Murarkar SK et $\mathrm{al}^{7}$ but consistent with other similar studies ${ }^{13,14}$.

In this study $53 \%$ respondents were using different types of contraceptives and $47 \%$ were not using any contraceptives. Prevalence of contraceptive user found in this study was consistent with the family planning bulletin data 2018 but lower than the study done by Sultana et $\mathrm{al}^{15}$ where $86.42 \%$ were usedcontraceptivedevice and $13.58 \%$ were not used. Among the contraceptive users $60.4 \%$ were using OCP, $15.8 \%$ using 
condom this finding was consistent with similar studies ${ }^{7,16}$ but was not consistent with other studies ${ }^{5,9}$. In this study permanent method of contraceptive users were only $4.4 \%$ and $3.1 \%$ of them were female this finding were consistent with similar studies ${ }^{10,13}$. Most of the respondent got information about contraceptives from family planning workers or their relatives, this finding consistent with similar studies in Bangladesh ${ }^{11,15}$.

In this study, injectable, implant and IUD users were $15.8 \%$, $5.6 \%$ and $4.4 \%$ respectively; these findings were consistent with similar studies ${ }^{6,16}$. Almost half of the respondents got information about contraceptives from the family planning workers this finding conforms with other similar studies ${ }^{8,14}$ in Bangladesh. From this study, it revealed is that male partners are not only taking less responsibility for contraceptive use but also some cases they are barring to use contraceptives. This study also reveals that misconception about the side effects and religious factors also barring to use contraceptives; this finding consistent with other studies ${ }^{6,12}$.

\section{Conclusion}

Prevalence of contraceptive use in Chattogram Hill Tract is lower than the overall rate of the country. Male partners are not only taking less responsibility for contraceptive use but also some cases they are barring to use contraceptives. Fear of side effects and religious factors are important factors to bar using contraceptives. Appropriate measure should be taken to increase the contraceptive use rate so that total fertility can be controlled.

\section{References}

1. WHO, Women of South-East Asia"A Health profile." Women's health status. Bangladesh (1998) South-East Asiaregion, New Delhi 2002.

2. Mansur AMSA, Chowdhury S, Rezaul KM et al. Unmet needs of familyplanning and practice of family planning in a selected urban to rural migratedpopulation of Dhaka city; Journal of family and reproductive health 2012; 6(3):115-22.

3. Ferdousi SK, Jabbar MA, Et el. Unmet need of family planning among rural women in Bangladesh. J Dhaka Med Coll 2010; 19(1):11-5.

4. Chaudhury HR. Unmetneed for contraceptionin South Asia: Levels, Trendsand Determinants. Asia Pacific Pop Journal 2001; 16(3):3-22.
5. Qazi HA, Hashmi A, Raza SA et al. Contraceptive methods and factors associated with modern contraceptive in use, Journal of family andreproductive health 2010; 4(1):41-5.

6. Kabir A, Islam MN, Chowdhury AA et al. Unmet Need for Family Planning among Married Women: Experience from Rural and Urban Communities. Faridpur Med Coll J 2013; 8(1):26-30.

7. Murarkar SK, Soundale SG, Lakade RN. Study of contraceptive practices and reasonsfor not accepting contraceptives in rural India: Chanai village as a case study. Indian Journal of science and technology 2011; 4(8):915-6.

8. NIPORT. Mitra and Associates, and Macro International. Bangladesh Demographic and Health Surrvey, 2007; preliminary report, Dhaka, Bangladesh.

9. Uddin ME, Ferdous Z. Gender of birth control method practice in sexual behavior in Bangladesh. Antrocom 2009; 5(2):87-91.

10. Tajina S. Study on knowledge and practice of contraception among lactating mother at MCH centre of Dhaka cantonment (Dissertation) 2001:72-4.

11. Kamal N, Mohsena M. Twenty years of field visits by FP workers in Bangladesh: Are they still needed? The Journal of Family Welfare 2011; 57(1):10-7.

12. Casterline JB and Sinding SW. Unmet need for family planning in developing countries and implications for population policy. Population and Development Review 2000; 26(4):691-723.

13. Tuladhar $H$, Marahatta R. Awareness and practice of family planning methods in women attending Gyne OPD at Nepal Medical College Teaching Hospital. Nepal Medical College Journal 2008; 10(3):184-91.

14. Pradhan J, Dwivedi R. Why Unmet Need for Family Planning Remains High in Bangladesh: A Community Level Analysis. J Women's Health Care 2015; 4:290.

15. Sultana S, Jahan MS, Islam MM. Contraceptive acceptance among eligible couples residing in Rajshahi City Corporation. Journal of teachers Association 2007; 20(1):11-6.

16. Hanifi SMM, Bhuiya A. Family-planning services in a low performing rural area of Bangladesh: Insights from field observations, Journal of health population and nutrition 2001; 19(3):209-14. 